\title{
The Role of Human Papillomavirus in Cervical Cancer
}

\section{Luiza Wójcik ${ }^{1 \#}$, Dariusz Samulak ${ }^{2,3 \#, ~ M a r i a n n a ~ M a k o w s k a 4, ~ H a n n a ~ R o m a n o w i c z ~}{ }^{1}$, Zbigniew Kojs ${ }^{5}$, Beata Smolarz ${ }^{1 *}$ and Magdalena M Michalska ${ }^{2,3}$}

${ }^{1}$ Laboratory of Cancer Genetics, Department of Pathology, Polish Mother's Memorial Hospital Research Institute, Rzgowska, Poland

${ }^{2}$ Department of Obstetrics and Gynaecology, Regional Hospital in Kalisz, Poland

${ }^{3}$ The President Stanisław Wojciechowski State University of Applied Sciences in Kalisz, Poland

${ }^{4}$ Klinikum Bad Saarow, Germany

${ }^{5}$ Oncological Gynaecology Chair, Oncology Centre-Maria Skłodowska-Curie Institute, Cracow Branch, Poland

${ }^{\#}$ Equal contribution.

*Corresponding author: Beata Smolarz, Laboratory of Cancer Genetics, Department of Pathology, Institute of Polish Mother's Memorial Hospital, Rzgowska 281/289, 93-338 Lodz, Poland, Tel: +48-42-271-1287

\begin{abstract}
Long-term infection with human papillomavirus (HPV) is the cause of cervical cancer and its precursor - cervical intraepithelial neoplasia (CIN). The presence of HPV infection can be presumed in more than $99 \%$ of cases of cervical cancer worldwide. The introduction of DNA testing for the presence of HPV has increased the effectiveness of screening programs for the detection of this cancer. This article contains the latest reports on the structure, function and role of HPV in the development of cervical cancer. It was also underlined the importance of performing molecular tests for the presence of HPV DNA as a more sensitive and the most accurate method of detecting the threat posed by infection with this oncovirus. The review also highlights the most beneficial prophylactic algorithm, which should be guided by gynecologists during the diagnosis, individual clinical cases.
\end{abstract}

\section{Keywords}

HPV, Cervical cancer, Virus, Carcinogenesis, Oncovirus

\section{Introduction}

In December 2018, it will pass exactly 10 years from the day Professor Harald zur Hausen, a German researcher, virologist and physician received the Nobel Prize in physiology and medicine, for a breakthrough discovery of showing the irrefutable correlation between human HPV (Human Papillomavirus) and the occurrence of neoplastic lesions in normal cells, primarily the cervix [1]. Describing this phenomenon seems even more important, given that until the late 1970s, Papillomaviruses (PVs) were treated in a marginal way, as they were only attributed to the development of benign skin lesions, most commonly in the form of human warts and some mammals. The development of techniques of genetic engineering and molecular biology that took place in the 80 's undoubtedly contributed to the expansion of knowledge about HPV. Thanks to the current polymerase chain reaction (PCR) technique (Polymerase Chain Reaction), it has been possible to discover and describe over 200 types of this virus, of which in about 150 cases the isolation and complete sequencing of viral genomes has been made. Moreover, it has been proven that HPV types are molecularly quite divergent, and individual viral genomes evolve at a similarly slow pace as in the genomes of their hosts [2-4].

The modern HPV taxonomy is based primarily on the assessment of changes that occur in the evolution of viruses, and not on their characteristic phenotypic traits. This direction of research is influenced by the fact that various, often very phylogenetically distant HPV types may be associated with the induction of similar symptoms. A perfect example of this phenomenon are HPV16 and HPV18, both highly oncogenic types (occurring in pair or individually), having in any medium, provided the original author and source are credited. 
an indisputable effect on the development of cervical cancer. They are definitely less related to each other than to the types of virus whose presence or impact on the carcinogenesis of this organ has never been confirmed [3].

The unprotected HPV virion is a circular, covalently closed dsDNA molecule (double-stranded DNA) of approximately $8 \mathrm{kbp}$, with only one coding thread. Capsid is a form consisting of the following structures:

- L, so-called Late Genes - L1 and L2, which are also assigned a function related to the virus's entry into epithelial cells, the assembly and release of posterior virions and the infectivity of the molecule,

- E, so-called Early Genes - E1, E2, E4, E5, E6, E7, which encode regulatory proteins, thus corresponding to the survival of the virus in the host cell, initiation of viral genome replication, or activation of the lytic cycle,
- LCR, so-called long regulatory region - taking part, among others, in virus replication (Figure 1) [3,5,6].

By sequencing the individual types of Papillomaviruses that scientists isolated from human cells (i.e. HPVs), the viruses were divided into five groups ( $\alpha, \beta$, $\nu, \mu, v)$, differing mainly from the life cycle and diseases caused by them. Most of them cause low-invasive infections in people with an optimal level of immunity, which is certainly related to the fact that the interactions between host cells and individual types of PVs have been co-motivating for hundreds of years. This led to the phenomenon in which the virus adapting to the host, can carry out and end its life cycle, without causing visible disease and at the same time remaining in the population [4].

Clinically the most important types of virus belong to the alpha-Papillomaviruses group ( $\alpha$-PVs). It is said then about viruses that are imperative of changes in

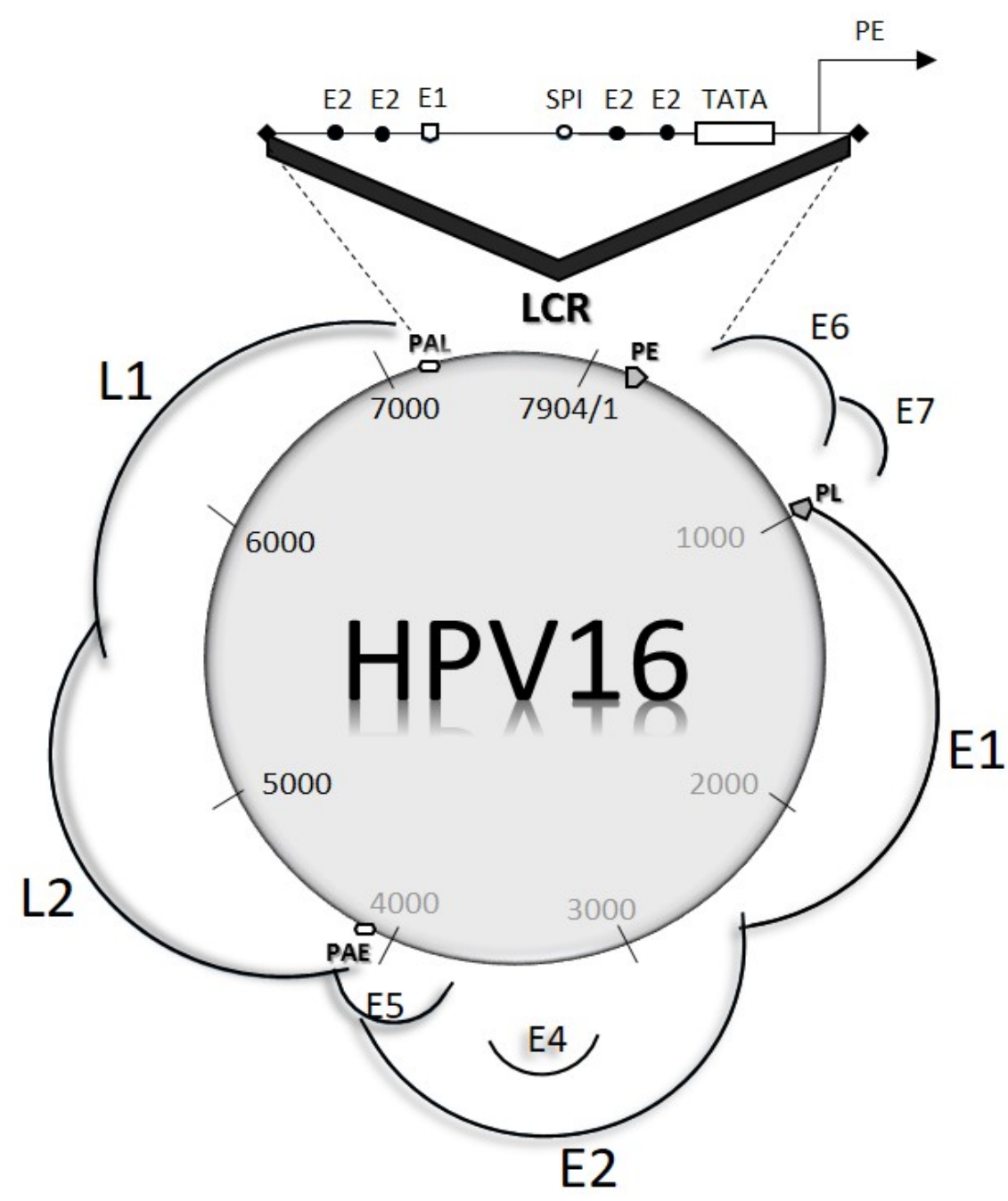

Figure 1: HPV 16 genome, as an example of a typical molecular structure for high-oncogenic viruses. Genes building a molecule encode a large number of protein products resulting from mRNA splicing. The LCR section contains binding sites for cellular transcription factors (SPI). Also distinguished are characteristic promoter structures (PE - Early Promtor, $P$ - Late Promotor), responsible for regulating the expression of mRNA molecules, differentiated as a result of splicing, during epithelial cell division. PAE (Proximal Early Polyadenylation Signal) and PAL (distal Late Poliadenylation Signal) responsible for "pointing" space in the early and late polyadenylation site in the genome, i.e. the modification of the mRNA in eukaryotic cells. 
the mucous membrane or genital organs. They were also divided into subgroups related to the level of risk and oncogenic potential that is associated with infection with these viruses. The viruses were divided into high-risk (hrHPV) and low-risk viruses (Ir-HPV) $[3,7,8]$.

The gateway to HPV infection is the formation of a minute of the basal layer of squamous epithelial cells and mucous membranes into which the virus is tropism. After binding to the appropriate receptor on the epithelial cell surface (some data suggest that the receptors may be heparin sulfate or $\alpha 6 \beta 4$ integrins), for which the L1 structural protein corresponds, the virus performs a productive replication cycle [9]. Its course is conditioned by the efficiency of the epithelial maturation process, specific systemic and cellular factors as well as viral proteins $[9,10]$. The early structural proteins of the virus play a key role in the infection. E5 oncoprotein induces the activity of an enzyme inducing the process of cellular apoptosis COX-2. The E6 protein binds to the $\mathrm{p} 53$ protein, which in the host cell is one of the key elements regulating the cell cycle, and the resulting E6-p53 complex excludes p53-dependent regulation of cell division processes, resulting in a state of instability at the chromosomal level, thus increasing the degree of cellular mutation, having a direct impact on its proliferation and the development of cancerous transformation. In addition, E6 forms complex structures with other proteins that are involved, for example, in DNA repair mechanisms or cell cycle control mechanisms (e.g., TNFR-1, called Tumor Necrosisi Factor Receptor 1, MGMT, or 06-Methylguainine-DNA Methyltransferase). In turn, E7 oncoprotein binds to the Rb (Retinoblastoma protein) suppressor protein (in addition to the $\mathrm{p} 107$ and $\mathrm{p} 130$ proteins), which is responsible for maintaining the cell in the $\mathrm{G} 1$ phase of the cycle. The resulting complex implies the release of E2F, which is responsible for above-average cell division and transcription, directing the cell to the $S$ phase of the cycle, which leads to its immortalization $[10,11]$. Interestingly, HPV has also developed mechanisms that help avoid immune responses from the host. This is due to the activity of structural early proteins E6 and E7, which implicating the excitation of translocations of the IRF-2 and IRF-3 (Interferon Regulatory Factor) genes, reduce the production of IFR $\alpha$ and IFN $\beta$, which are directly involved in the reduction of virus multiplication. In addition, these oncoproteins disrupt the expression of TLRs (Toll-like Receptors) responsible for the detection of pathogens in the host organism and activation of the above-mentioned interferons [12].

\section{HPV virus and its importance in the process of cancer}

As mentioned, many HPV types are distinguished, whose presence has been confirmed both in the presence of clinically harmless symptoms (warts), and in cases in which HPV has been assigned the effect on the development of cancer among men and women (Table 1) [1]. It has been demonstrated that HPV is primarily a precursor to the development of cervical carcinogenesis (about $70 \%$ of all cancers are caused by the most severe HPV16 and HPV18, with $99.7 \%$ of cancer cases being detected) [6]. In addition, its oncogenic effect on squamous cells was confirmed correctly in the vulva, vagina and penis (in about $40 \%$ of cases, the presence of a hrHPV type associated with these conditions was detected), but also in the throat, larynx, oral cavity (mainly the tongue root) palatine

Table 1: Table showing the division of HPV due to the level of their oncogenicity and the type of diseases caused by these viruses.

\begin{tabular}{|c|c|c|c|}
\hline \multicolumn{2}{|c|}{ Type of HPV } & \multirow{2}{*}{$\begin{array}{l}\text { Oncogenicitytype } \\
\text { High-risk HPV }\end{array}$} & \multirow[b]{2}{*}{$\begin{array}{l}\text { Clinicalproperties } \\
\text { They cause malignant changes within the mucous membrane. } \\
\text { Some (mainly HPV18) are more common in adenocarcinoma } \\
\text { than in cervical squamous cell carcinoma. In the case of other } \\
\text { high-risk virus types (primarily HPV16 - the most common } \\
\text { pathogen that causes cervical cancer), the opposite is true. }\end{array}$} \\
\hline $\begin{array}{l}\text { HPV16, } \\
\text { HPV31, } \\
\text { HPV35, } \\
\text { HPV45, } \\
\text { HPV58, } \\
\text { HPV67, } \\
\text { HPV70, }\end{array}$ & $\begin{array}{l}\text { HPV18, } \\
\text { HPV33, } \\
\text { HPV39, } \\
\text { HPV52, } \\
\text { HPV59, } \\
\text { HPV68, }\end{array}$ & & \\
\hline $\begin{array}{l}\text { HPV26, } \\
\text { HPV51, } \\
\text { HPV56, } \\
\text { HPV69, }\end{array}$ & $\begin{array}{l}\text { HPV30, } \\
\text { HPV53, } \\
\text { HPV66, }\end{array}$ & High-risk HPV & $\begin{array}{l}\text { They cause malignant or mild changes within the mucous } \\
\text { membrane. }\end{array}$ \\
\hline \multicolumn{2}{|c|}{ HPV7, HPV40, HPV43 } & Low-risk HPV & $\begin{array}{l}\text { They cause the occurrence of skin warts, often genital warts of } \\
\text { children }\end{array}$ \\
\hline \multicolumn{2}{|c|}{ HPV7, HPV40, HPV43 } & Low-risk HPV & $\begin{array}{l}\text { They cause mild changes in mucous membranes and skin. } \\
\text { They often occur in people infected with HIV (Human Immuno- } \\
\text { deficiency Virus). }\end{array}$ \\
\hline \multicolumn{2}{|c|}{$\begin{array}{l}\text { HPV6, HPV11, HPV13, } \\
\text { HPV44, HPV74 }\end{array}$} & Low-risk HPV & $\begin{array}{l}\text { They induce benign mucosal changes in the genital area among } \\
\text { men and women, genital warts and laryngeal papillomas. Some } \\
\text { of these changes can go from a benign to malignant state. }\end{array}$ \\
\hline \multicolumn{2}{|c|}{ HPV5, HPV8 } & Low-risk HPV & $\begin{array}{l}\text { Their presence has been demonstrated in patients with } \\
\text { immunosuppression and with Epidermodysplasia verruciformis. }\end{array}$ \\
\hline
\end{tabular}


tonsils, upper part of the esophagus, conjunctivitis, paranasal sinuses and lungs [11]. It is worth noting that in the case of cancer last of the above mentioned organs, detection of hrHPV estimates in the range of 0 to $78 \%$ [13]. The development of a patient's malignant disease is also influenced by environmental factors, mainly the place of residence, lack of a healthy lifestyle, including drinking excessive amounts of alcohol and smoking, but also the type of cancer being analyzed or genetic determinants of the patient. Similar conclusions were obtained when analyzing cases of head and neck cancer, and it was also proven that tumors of those parts of the body that HPV contributed to (mainly 16 and 18 ) respond better to treatment than those on which the virus had no effect on the virus [14]. What is also interesting, the presence of the virus (including 5 and 8) was also confirmed in people with rare genetic (recessive autosomal) skin disease - Epidermodysplasia verruciformis (EV) [15].

\section{The role of HPV in the development of cervical cancer}

Cervical cancer is the fourth most common cancer among women in the world, causing annually about 275,000 deaths $[16,17]$. There are many factors affecting the development of this life-threatening disease, such as the socio-economic status, the moment of sexual intercourse, alcohol consumption or smoking, as well as genetic load, immunosuppression and a large number of pregnancies and births (especially for young women) [18]. However, the most important factor that has a huge impact on the development of cervical cancer is primarily persistent infection with
hrHPV (mainly types 16 and 18), which can lead to uncontrolled course of infection (Figure 2). In the data analysis of a multicentre comparative case study of the International Agency for Research on Cancer (IARC), the odds ratio (OR) for squamous cell carcinoma due to HPV infection was 158.2, with the analysis limited to studies using approved HPV detection techniques [19]. In this study, the odds ratio for cervical cancer ranged from 109 to 276 in studies from different parts of the world [19].

HPV is transmitted most often through sex, infecting 6.2 million new people each year, which makes it one of the most frequently transmitted viruses in the world. Regardless of gender, and depending on the degree of sexual activity, the risk of HPV infection is around $50 \%$ throughout life (both in women and in men) [1]. Women most often get infected with a virus between 15 and 25 years of age. Most infections among immunocompetent women pass asymptomatic after about 24 months. It is worth noting that the lack of symptoms is a hallmark of HPV-induced infection, which undoubtedly contributes to ignoring the patient's regular tests confirming the presence or absence of pathogen threat, but also allowing the virus to initiate a persistent infection [8]. If the infection does not subside, within $10-30$ years of viral replication will be accompanied by neoplastic changes, concerning the endothelium of the cervix, so-called CIN (Cervical Intraephitelial Neoplasia). In histopathological findings, they are divided into the degree of advanced neoplasia to low-grade dysplasia, referred to as CIN-1, medium-sized neoplasia is $\mathrm{CIN}-2$ and precancerous stage referred to as $\mathrm{CIN}-3$. In addition, can-

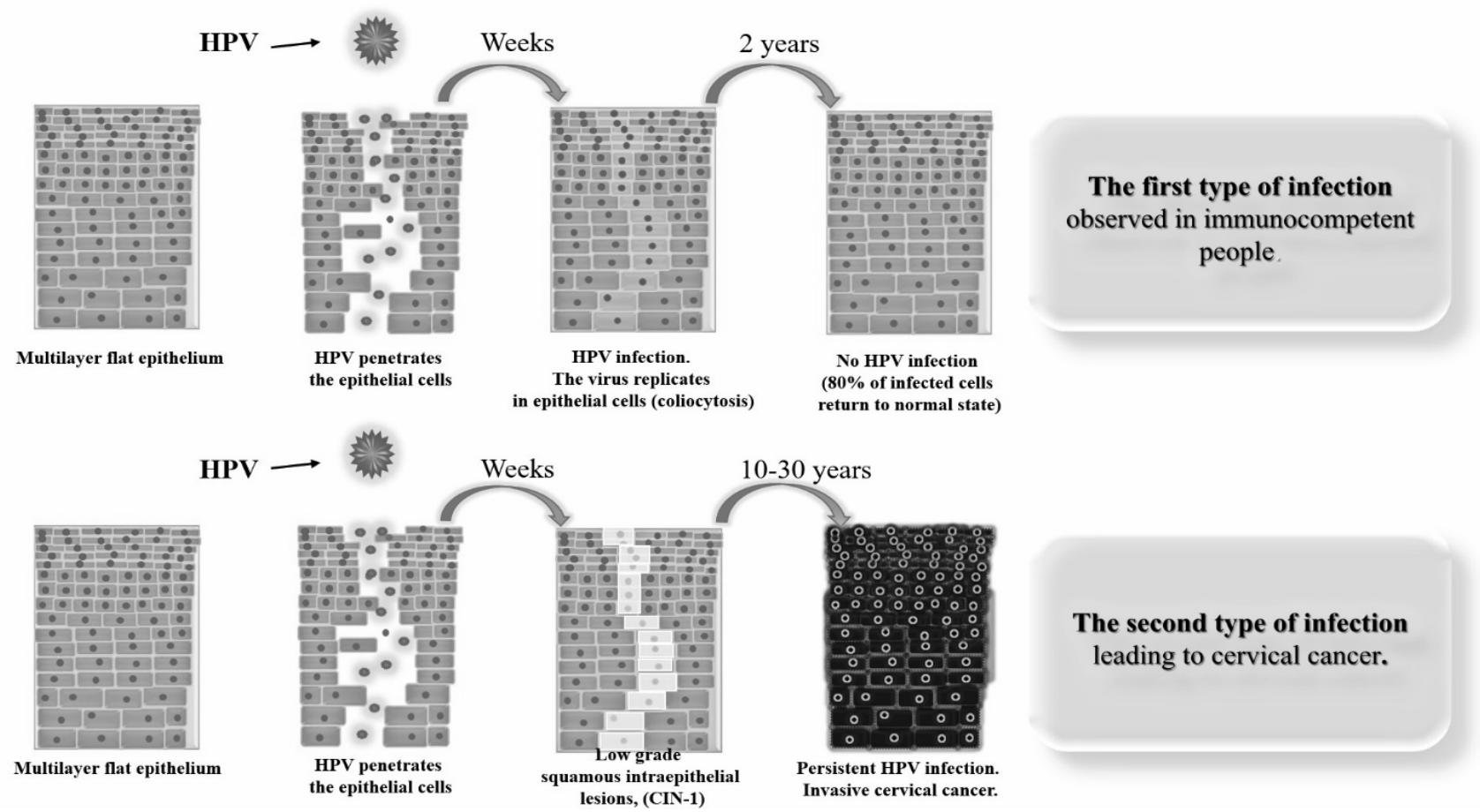

Figure 2: Schematic representation of the mechanism of HPV infection in the case of immunocompetent persons (top) and in the case of persistent infection leading to cervical cancer (down). 


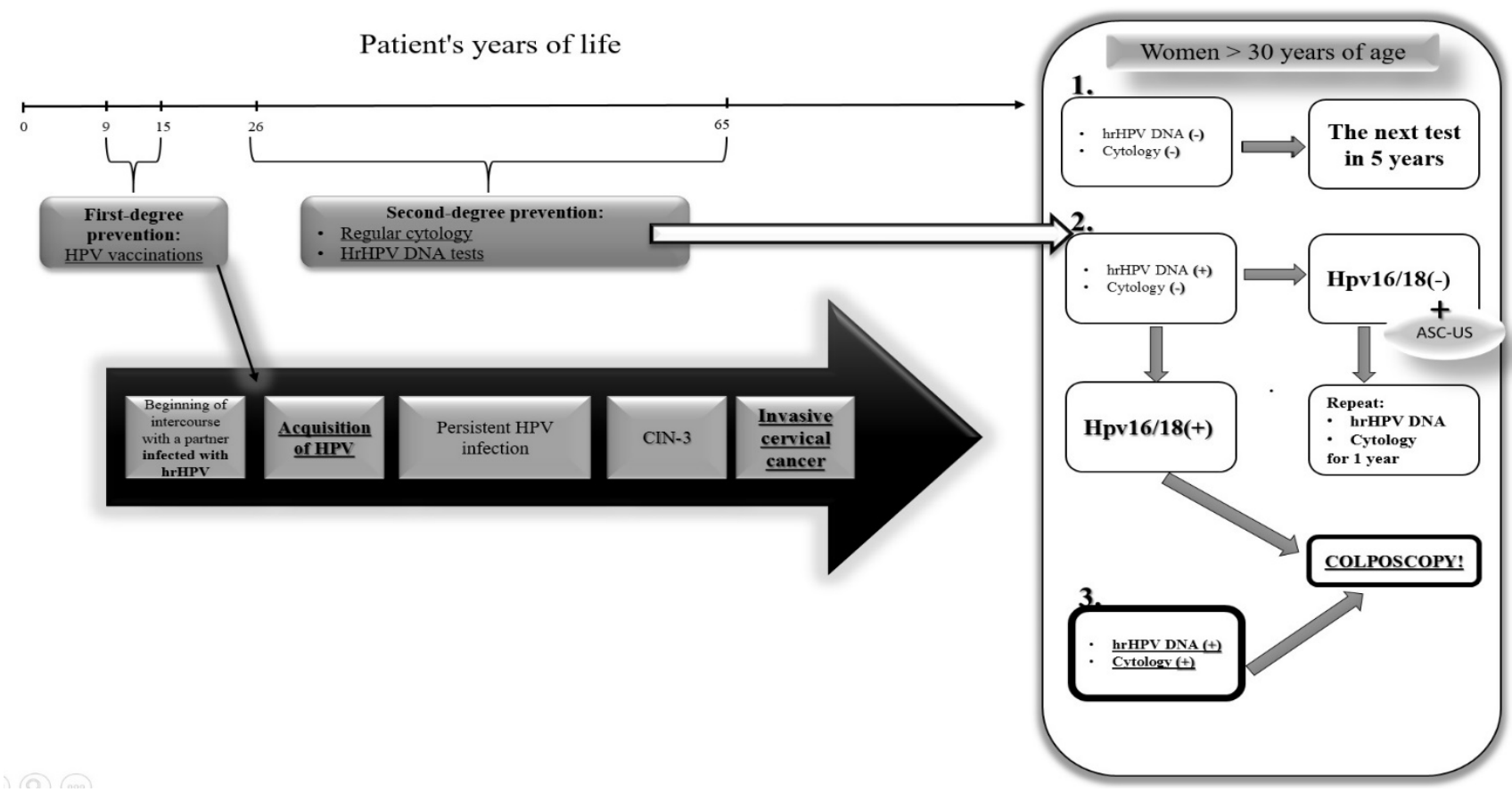

Figure 3: The diagram presents the possibility of developing cancer caused by persistent hrHPV infection, in a hypothetical situation when the patient was not vaccinated at the right time (before sexual intercourse) and a basic pattern of gynecological procedures, providing for several variants. Variant number 1 assumes negative results of both cytological examination and hrHPV DNA tests. In this situation, the patient is referred for further tests in the standard course of action, i.e. for 5 years. In variant number 2 the hrHPV test is negative, but additionally there was a situation when the cytology did not show the presence of cancerous cells, however, it revealed the ASC-US (Atypical Squamous Cells of Undetermined Significante), indicative of the presence of inflammation in the cervix. In this situation, the patient is referred for further tests for the year. If the cytology was correct, but the results of the hrHPV molecular tests are adding, the standard procedure says that an experienced gynecologist must immediately refer the patient to a colposcopic examination to detect pre-invasive cervical cancer. Variant 3 is the worst situation in which both cytology showed disturbing neoplastic changes and what additionally confirmed molecular tests for the presence of hrHPV DNA. It is necessary to immediately perform a colposcopy [20].

cer stages are also distinguished, which are classified depending on the stage of cancer disease, i.e. from I to IV $[1,20]$.

However, taking into account the current state of knowledge and the current view on the etiology of cervical cancer, it was found that cytological examinations and their evaluation system (used since the 1950s, referred to as the "golden standard", the Papanicolau scale - Pap Smear), do not constitute the entire diagnostic set that the patient can use. Currently, it is also recommended to perform diagnostic tests extended with a molecular algorithm. Thanks to it, it is possible not only to detect the HPV virus inthe cytological material, but also to determine what specific types of virus are present in it, highlighting above all the most dangerous from the point of view of the implications of the carcinogenesis process. It is also worth paying attention to the fact, which is related to the limitations of the test, which is cytology. This test is characterized by relatively low sensitivity and repeatability, which leads to variable accuracy of the obtained results. In addition, repeating the cytological examination, a greater number of false diagnoses were noted, increasing in a unit of time. What's more, cytology works mainly in the detection of cervical squamous cell carcinoma, in addition to which cervical adenocarcinoma is also present, which unfortunately does not detect this. It is not surprising then that for many years attempts have been made to "support" prophylactic activities concerning cervical research, based mainly on cytology, adding to this standard characterized by significantly higher quality and sensitivity of molecular tests (Figure 3) $[8,16,17]$.

It is impossible not to notice more clearly the disproportion characterizing the global incidence rate of cervical cancer. It is abnormally higher among women living in undeveloped areas ( $85 \%$ of cases come from these areas), above all Sub-Saharan Africa, Central America and South-East Asia. A clear difference between countries (areas) considered to be developed, and those undeveloped or developing, is explained, among others differences in the risk of hrHPV infection, the level of consciousness of patients and the system of prevention and prevention of this disease. The lowest rates of both morbidity and, above all, mortality are observed in countries where an efficiently operating screening program is available, which results in the morbidity and mortality from cervical cancer falling for years $[16,17]$.

In both developing and developed countries, a 
prevention program against hrHPV with vaccines is also being carried out. Using data that confirmed that in $60 \%$ of cases of cervical cancer HPV16 was detected, 18\% HPV18, 8\% HPV45 and 5\% HPV31 developed vaccines containing purified virus-like particles of VLP (Virus-like Particles), for example the above-mentioned types of high-risk viruses $[1,8]$. The first approved vaccine was a quadrivalent formulation called Gardasil, now replaced with the newest generation Gardasil9 vaccine (nine-valent vaccine, against HPV infections $16,18,6,11,31,33,45,52,58)$, whose efficacy in preventing cervical cancer is comparable with the second Cervarix vaccine on the market (bivalent vaccine against HPV 16 and 18 infections). It is recommended to vaccinate adolescent girls (915 years), before starting sexual intercourse, giving them the preparation in two doses, preferably every six months (above 15 years of age, WHO recommends the administration of 3 doses of the vaccine). It is assumed that the vaccine will protect the patient from HPV infection until she is ready to begin routine cytological tests, preferably in conjunction with HPV molecular tests, proving at least the persistence of high HPV antibodies for 10 years after the injection of Cervarix [21]. It is true that $80 \%$ of cancers caused by persistent infection hrHPV cancer causes changes in the cervix in women, so it is also worth noting that it also recommends vaccination of young boys (1112 years). Then it takes into account the transfer of viral particles, occurring mainly through sexual contact, and even statistics on head and neck cancer, or penis in men affected by the oncogenic HPV infection [22]. 12 years after the introduction of HPV vaccines recommended by WHO (the World Health Organization), the vaccine prophylaxis program functions in 74 countries, without confirming the occurrence of any side effects of the preparation [23]. In Poland, vaccinations against HPV are recommended, but they are not financed from the budget of the Ministry of Health. However, it is worth checking the current Local Preventive Programs, in which the schedule may include vaccinations against HPV (in 2018, 9 provinces joined the vaccination program) [24].

\section{Summary}

In the prevention of cervical cancer, it is not only important to detect changes early, but also to identify factors that have the most probable etiopathogenetic relationship to the carcinogenesis process within this organ. By detecting and then diagnosing HPV infected people, a high-oncology risk group can be identified, which can then be subjected to tighter control. Attempts to estimate the prevalence of HPV infection among women with subclinical or latent disease results in different results, depending on the population studied and the method used to detect the virus. Human viruses from the Papilloma family do not multiply in cell cultures, so far no model of infection of animals and breeding of viruses has been developed. Due to the difficulty of obtaining a viral antigen, standard serological methods cannot be used in in vitro cultures. Detection of HPV infection has become possible only after the introduction of methods used in molecular biology. The highest percentage of infections is diagnosed using a PCR reaction that is characterized by the highest sensitivity among all currently known molecular biology techniques. It allows you to demonstrate the presence of one copy of HPV on 105-106 cells. PCR is now becoming a common diagnostic technique that is used in many laboratories. The results obtained on this basis are comparable and allow to some extent to avoid their false interpretation. The introduction of DNA testing to detect the presence of HPV virus has increased the effectiveness of screening programs for detection of cervical cancer by prior detection of high-risk changes in women over 30 years of age with the NILM (Negative for Intaepithelial Lesion or Malignancy) cytology test and reducing the need for unnecessary colposcopy and treatment in patients after 21 years with ASC-US result of cytological examination [19,25-28]. In addition, the sensitivity of the test for the presence of HPV DNA as compared to PAP-smear in the detection of a high-grade disease in the population undergoing screening has been repeatedly confirmed. DNA testing for the presence of HPV virus with proven higher sensitivity was proposed and used as the primary first-line screening test in some screening programs.

\section{References}

1. Hinrle L (2009) Zakażenia wirusem HPV-problem medyczny i społeczny. Ginekol Prakt 17: 8-12.

2. ZurHausen $\mathrm{H}$ (2002) Papillomaviruses and cancer; from basic studies to clinical application. Nat Rev Cancer 2: 342350.

3. Bernard HU (2004) The clinical importance of the nomenclature, evolutnion and taxonomy of human papillomariruses. J Virol 32: S1-S6.

4. Doorbar J, Quint W, Banks L, Bravo IG, Stoler M, et al. (2012) The biology and Life-Cycle of Human Papiillomaviruses. Vaccine 30: F55-F70.

5. Öberg D, Fay J, Lambkin H, Schwartz S (2005) A downstream polyadenylation element in human papillomavirus type 16 L2 encode multiple GGG motifs and interacts with hnRNP H. J Virol 79: 9254-9269.

6. Broniarczyk J, Koczorowska MM, Durzyńska J, Warowicka A, Goździcka-Józefiak A (2010) Struktura i właściwości wirusa brodawczaka ludzkiego. Biotechnologia 3: 126-145.

7. De Villiers EM, Fauquet C, Broker TR, Bernard HU, zurHausen H (2004) Classification of papillomaviruses. Virol 324: $17-27$

8. Molijn A, Berhard K, Quint W, van Doorn LJ (2005) Molecular diagnosis of human papillomavirus (HPV) infections. J Clin Virol 32: S43-S51.

9. Shafti-Keramat S, Handisurya A, Kriehuber E, Meneguzzi G, Slupetzky K, et al. (2003) Different heparan sulfate proteoglycans serve as cellular receptors for human papillomaviruses. J Virol 77: 13125-13135. 
10. Ramakrishnan S, Patricia S, Mathan G (2015) Overview of high-risk HPV'S 16 and 18 infected cervical cancer: pathogenesis to prevention. Biomed Pharmacother 70: 103-110.

11. Morshed K (2004) Udział wirusa brodawczaka ludzkiego (HPV) w etiopatogenezie nowotworów głowy i szyi. Otorynolaryngologia 3: 91-96.

12. Boccardo E, Lepique AP, Villa LL (2010) Therole of inflamation in HPV carcinogenesis. Carcinogenesis 31: 19051912.

13. Zhai K, Ding J, Shi HZ (2015) HPV and lung cancer risk: A meta-analysis. J Clin Virol 63: 84-90.

14. Syrjänen S (2007) Human Papillomaviruises in Head and Neck Carcinomas. N Engl J Med 356: 1993-1995.

15. Żaba R, Kaszewski S (2000) Epidermoplasiaverruciformis (EV). Przew Lek 4: 110-113.

16. Dijkstra MG, Snijders JF, Arbyn M, Rijkaart DC, Berghof J, et al. (2014) Cervical cancer screening: $n$ the way to a shift from cytology to full molecular screening. Annals of Oncology 25: 927-935.

17. Reels J, Jones D, Chen H, Macleod U (2018) Interferations to improve the uptake of cervical cancer screening among lower socioeconomic gropus: a systematic review. PrevMed 111: 323-335.

18. Stefanek A, Durka P (2014) Poziom świadomości kobiet na temat profilaktyki raka szyjki macicy. Polski Przegląd Nauk o Zdrowiu 1.

19. Munoz N, Bosch FX, de Sanjose S, Herrero R, Castellsague $X$, et al. (2003) Epidemiologic classification of Human Papillomavirus types associated with cervical cancer. $\mathrm{N} \mathrm{J}$ Engl Med 348: 518-527.

20. Ronoco G, Dillner J, Elfstrom KM, Tunesi S, Snijders PJF, et al. (2014) Efficacy of HPV-based screening for prevention of invasive cervical cancer: follow-up of four European randomised controlled trials. Lancet 383: 524-532.

21. Harper DM, DeMars LR (2017) HPV vaccins-A review of the first decade. Gynecologic Oncology 146: 196-204.

22. Verma R, Khanna P (2012) Human papilloma virus vaccines: need to be introduced in India. Hum Vaccin Immunother 9: 97-99.

23. Sabeena S, Bhat PV, Kamath V, Arunkumar G (2018) Global Human virus vaccine implementation: An update. J Obstet Gynaecol Res.

24. Data base.

25. Stoler MH, Castle PE, Solomon D, Schiffman M; American Society for Colposcopy and Cervical Pathology (2007) The expanded use of HPV testing in gynecologic practice per ASCCP-guided management requires the use of well-validated assays. Am J Clin Pathol 127: 335-337.

26. Ronco G, Giorgi-Rossi P, Carozzi F, Confortini M, Dalla Palma P, et al. (2010) Efficacy of human papillomavirus testing for the detection of invasive cervical cancers and cervical intraepithelial neoplasia: a randomized controlled trial. Lancet Oncol 11: 249-257.

27. Saslow D, Solomon D, Lawson HW, Killackey M, Kulasingam SL, et al. (2012) American Cancer Society, American Society for Colposcopy and Cervical Pathology, and American Society for Clinical Pathology Screening Guidelines for the Prevention and Early Detection of Cervical Cancer. Am J ClinPathol 137: 516-542.

28. Stoler MH, Wright TC Jr, Sharma A, Zhang G, Apple R, et al. (2012) The Interplay of age stratification and HPV testing on the predictive value of ASC-US cytology. Am J ClinPathol 137: 295-303. 